\title{
Prognostic and predictive biomarkers for metastatic renal cell carcinoma
}

\author{
Logan G. Briggs' ${ }^{1}$ Eugene B. Cone ${ }^{1,2}$, Richard J. Lee ${ }^{1,3}$, Michael L. Blute ${ }^{1,2}$ \\ ${ }^{1}$ Harvard Medical School, Boston, MA 02114, USA. \\ 2Department of Urology, Massachusetts General Hospital, Boston, MA 02114, USA. \\ ${ }^{3}$ Department of Medicine, Division of Hematology/Oncology, Massachusetts General Hospital, Boston, MA 02114, USA.
}

Correspondence to: Prof. Michael L. Blute, Urology Associates, Massachusetts General Hospital, 165 Cambridge Street, CPZ-7, Boston, MA 02114, USA. E-mail: MBLUTE@mgh.harvard.edu

\begin{abstract}
How to cite this article: Briggs LG, Cone EB, Lee RJ, Blute ML. Prognostic and predictive biomarkers for metastatic renal cell
\end{abstract} carcinoma. J Cancer Metastasis Treat 2021;7:46. https://dx.doi.org/10.20517/2394-4722.2021.84

Received: 31 Mar 2021 First Decision: 9 Jun 2021 Revised: 15 Jun 2021 Accepted: 25 Jun 2021 First online: 2 Jul 2021

Academic Editors: Lucio Miele, Hendrik Van Poppel Copy Editor: Xi-Jun Chen Production Editor: Xi-Jun Chen

\begin{abstract}
Several prognostic models incorporating serum biomarkers to estimate patient survival have been established for metastatic renal cell carcinoma. Interim advancements in biomarker research have highlighted much additional serum, gene mutation, genetic expression signatures, and histologic biomarkers that predict clinical outcomes and response to treatments. We, therefore, reviewed biomarkers associated with overall, cancer-specific, progressionfree, and disease-free survival, overall response, and time to treatment failure rate in adult populations with metastatic renal cell carcinoma. We reviewed human studies reporting associations between biomarkers and clinical outcomes. Data were abstracted via standardized form, then reported with hazard ratios and confidence intervals where appropriate, subdivided by biomarker type (serum, gene mutation, genetic expression, and histologic). We identified a range of newer biomarkers that have clinical associations with prognostic and predictive outcomes. Beyond biomarkers used in modern risk models, those consistently associated with prognosis included serum levels of CAIX, COP-NLR, CRP, s-TATI, and VEGF, gene mutations in BAP1, CDKN2A, CIMP/FH, and TERT, gene expression of ERV and NQO1, and histologic macrophage infiltration and expression of CAIX and PDL1. Biomarkers consistently associated with the response to targeted antiangiogenic therapy included serum CRP, mutations in MET, PBRM-1, BAP1, and the mTOR pathway, TERT promoter mutations, and expression of PTEN and angiogenic gene signatures. Gene expression of $h E R V$, T-effector, and immunogenic signatures have been associated with improved response to immune checkpoint inhibition. Future models should incorporate wellstudied biomarkers to help clinicians predict outcomes and treatment responses for patients with metastatic renal cell carcinoma.
\end{abstract}


Keywords: Carcinoma, renal cell, biomarkers, precision medicine, patient-specific modeling, neoplasms

\section{INTRODUCTION}

Biomarkers are objective indicators of disease states that can be observed from outside the patient ${ }^{[1]}$. With advancements in proteomic and genomic analytics, biomarkers hold increasing promise for diseases with variable prognoses or treatment regimens, where they may predict outcomes and inform individualized medicine ${ }^{[2,3]}$. One such common disease is renal cell carcinoma (RCC), the eighth-most incident cancer in the United States ${ }^{[4]}$, responsible for 430,000 new cases and 180,000 deaths in 2020 worldwide $^{[5]}$. While the prognosis for localized RCC is favorable, with 5 -year survival rates up to $95 \%$ after surgical treatment, metastatic RCC (mRCC) is present in up to $16 \%$ of new RCC diagnoses and carries a poor prognosis with 5year survival rates as low as $12 \%^{[4,6,7]}$.

Historical treatment of mRCC can be broken into three eras. The initial treatments consisted of immunotherapy with agents such as interferon-alpha or high-dose interleukin-2, which were highly toxic and produced durable complete responses in a very small fraction $(<10 \%)$ of patients ${ }^{[8]}$. Further understanding of RCC cell growth pathways and immunogenicity of RCC led to further development. The second era of mRCC treatment includes targeted therapy such as $m$ TOR inhibitors and anti-angiogenic tyrosine kinase inhibitors (TKIs) against vascular endothelial growth factor (VEGF) or the VEGF receptor (VEGFR). Most recently, immunotherapy or immune checkpoint inhibitors (ICIs), which are monoclonal antibodies against immune checkpoint proteins such as programmed cell death 1 (PD-1), PD-ligand 1 (PDL1), and anti-cytotoxic T-lymphocyte-associate protein-4 (CTLA-4), have been employed with improved ORR and survival ${ }^{[9]}$.

Prognostic models have been developed and validated to estimate survival in the setting of mRCC. The most widely used models include the Memorial Sloan Kettering Cancer Center (MSKCC), validated by the Cleveland Clinic Foundation $(\mathrm{CCF})^{[1,0,11]}$, and the International Metastatic RCC Database Consortium (IMDC) Heng model and validation ${ }^{[12,13]}$, which predict poorer prognosis with elevated neutrophils or platelets, lower hemoglobin counts or Karnofsky performance status, and other similar metrics. While these models provide useful survival estimates, there has been rapid advancement in biomarker research predicting more specific clinical outcomes such as overall survival (OS), cancer-specific survival (CSS), progression-free survival (PFS), disease-free survival (DFS), or metastasis. Additional work has explored biomarkers capable of predicting a patient's overall response rate (ORR) or time to treatment failure (TTF) to a specific regimen.

We reviewed biomarkers associated with OS, CSS, PFS, DFS, TTF, and ORR in adults with metastatic RCC. Data were abstracted via standardized form, then reported with hazard ratios and confidence intervals where appropriate, subdivided by biomarker type (serum, gene mutation, genetic expression, and histologic). For the purposes of our review, we followed the convention of referring to biomarkers that are associated with PFS, DFS, OS, or other broad clinical outcomes independent of treatment received as "prognostic biomarkers". This contrasts with biomarkers that predict a response (or absence of a response) to a specific treatment, which are referred to as "predictive biomarkers". Included tables are limited to statistically significant findings, with both significant and non-significant findings found in supplemental materials. A list of abbreviations for included biomarkers can also be found in the supplement. 


\section{PROGNOSTIC BIOMARKERS}

Serum biomarkers, such as ALP, corrected calcium, Hg, LDH, neutrophil count, and platelets have been extensively validated as prognostic biomarkers for OS and CSS by MSKCC ${ }^{[10]}, \mathrm{CCF}^{[11]}, \mathrm{IMDC}^{[12]}$, Groupe Français d'Immunothérapie ${ }^{[14]}$, International Kidney Cancer Working Group ${ }^{[15]}$ and others [Table 1, Supplementary Table 1]. Additional promising serum biomarkers include elevated carbonic anhydrase IX (CAIX) being potentially prognostic of improved PFS and $\mathrm{OS}^{[16]}$, while elevated COP-NLR ${ }^{[17]}$, elevated $\mathrm{CRP}^{[18]}, \mathrm{s}^{-\mathrm{TATI}^{[19]} \text {, and VEGF }}{ }^{[15,16,20]}$ may be prognostic for decreased PFS and/or OS ${ }^{[19]}$. Conflicting or inconclusive evidence exists regarding Ras $21^{[21]}$, sVEGF- ${ }^{[16]}$, TIMP-1 mRNA ${ }^{[16,22]}$. For example, elevated TIMP-1 mRNA has been positively associated with metastasis and OS in one study ${ }^{[2]}$ but negatively associated with OS in another ${ }^{[16]}$.

Among certain patient populations, mutated alleles that may be prognostic for poorer OS or PFS compared to wild type (WT) include loss of function (LOF) mutations or alterations in $B A P 1^{[23]}, C D K N 2 A^{[24]}, C I M P$ $/ \mathrm{FH}^{[24]}$, and TERT $T^{[23]}$ [Table 2, Supplementary Table 2]. Limited evidence has linked tumor mutational burden (TMB) with poor OS and PFS; however, most has shown no significant association ${ }^{[25-30]}$. The prognostic value of PBRM-1 LOF mutations has proven inconsistent, with some studies reporting longer OS or PFS in patients receiving nivolumab ${ }^{[31,32]}$, but no significant difference in patients receiving everolimus, sunitinib, or combination therapy ${ }^{[27,28,32,33]}$. Limited evidence also suggests that OS may be longer in patients with PBRM-1 LOF mutations and pancreatic metastasis than without ${ }^{[33]}$. Additionally, PBRM-1 LOF mutations have been associated with less immunogenic, more angiogenic tumor microenvironments, which may portend a worse prognosis ${ }^{[33]}$. The prognostic value of PBRM-1 mutations as a marker of survival may depend on the specific treatment used. Conflicting or inconclusive evidence exists regarding whether mutated alleles in $E R V^{[25]}, m T O R^{[28]}$, and $V H L^{[28]}$ are prognostic for OS or PFS. Finally, SETD2 may be associated with metastatic spread to bone $\mathrm{e}^{[34]}$.

Expression of single genes and gene expression signatures (GES) may also be prognostic for OS and PFS [Table 2, Supplementary Table 2]. Increased expression of ERV has been shown to be prognostic for improved PFS ${ }^{[3,36]}$, while expression of NQO1 has been associated with shorter OS ${ }^{[24]}$. Expression of DUX4 GES has not been shown to be prognostic ${ }^{[28]}$. The prognostic value of GES IMmotion 150 Angio, IMmotion 150 Myeloid, IMmotion 150 Teff, Renal 101 Immuno, and Renal 101 Angio will be discussed separately, along with their predictive value ${ }^{[28,29]}$.

Finally, histologic biomarkers have shown prognostic value [Table 2, Supplementary Table 2]. High levels of CAIX have a demonstrated association with improved DFS ( $\mathrm{HR}=0.69, P=0.01)$, OS $(\mathrm{HR}=0.60, P=0.01)$, and CSS $(\mathrm{HR}=0.69, P=0.01)^{[21]}$; similarly, in a separate study, low levels of CAIX were linked to decreased CSS $(\mathrm{HR}=3.10, P<0.001)^{[37]}$. Additionally, given the complex interplay between T-cells and RCC cancer cells, the infiltration of various areas of tumors by CD8+ T-cells has been examined. While higher CD8+ Tcell density in tumor centers and invasive margins has been associated with improved PFS in patients receiving sunitinib, no significant difference was noted amongst patients receiving avelumab plus axitinib $^{[28]}$. On the other hand, macrophage infiltration has been associated with poorer OS and PFS in patients receiving anti-angiogenic TKI, though the limited study has examined macrophage infiltration and outcomes with other therapies ${ }^{[38]}$.

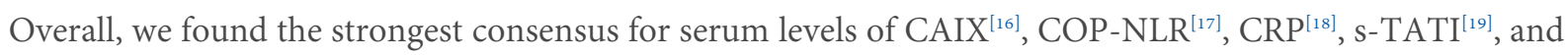
$\mathrm{VEGF}^{[15,16,20]}$, gene mutations in $B A P 1^{[23]}, C D K N 2 A^{[24]}, C I M P / \mathrm{FH}^{[24]}$, and $T E R T^{[23]}$, gene expression of $\mathrm{ERV}^{[3,36]}$, and $\mathrm{NQO}^{[24]}$, and histologic expression of $\mathrm{CAIX}^{[21,37]}$ and macrophage infiltration ${ }^{[38]}$ as prognostic biomarkers for OS and PFS. Tables 1 and 2, Supplementary Tables 1 and 2 list all identified data depicting 
Table 1. Serum prognostic biomarkers

\begin{tabular}{|c|c|c|c|c|}
\hline Serum biomarker & Cohort therapy or histology & PFS/DFS & OS (CSS) & $n$ \\
\hline \multirow[t]{2}{*}{ ALP (high vs. low) $)^{[15,59]}$} & Untreated & & $\mathrm{HR}=1.52, P=0.014$ & 416 \\
\hline & & & $\mathrm{RR}=1.46, P<0.0001$ & 2217 \\
\hline \multirow[t]{4}{*}{$\mathrm{Ca}$ (high vs. low) ${ }^{[10-12,59]}$} & INF $\alpha$ & & $\mathrm{RR}=1.93, P<0.0001$ & 463 \\
\hline & Untreated & & Shorter, $P<0.001$ & 308 \\
\hline & & & $\mathrm{HR}=2.01, P<0.001$ & 416 \\
\hline & & & $\mathrm{RR}=3.05, P<0.0001$ & 601 \\
\hline Ca (low vs. high $)^{[60]}$ & $N+$ Ip & & $\mathrm{HR}=0.63,95 \% \mathrm{Cl}: 0.46-0.86$ & 550 \\
\hline COP-NLR (high vs. low) ${ }^{[17]}$ & Por S & & $\mathrm{HR}=1.78, P=0.008$ & $276 \div$ \\
\hline CRP (high vs. low) ${ }^{[18]}$ & S & $\mathrm{HR}=2.48, P<0.05$ & $\mathrm{HR}=3.17, P<0.05$ & 200 \\
\hline $\mathrm{Hg}$ (high vs. low) ${ }^{[60]}$ & S & & $\mathrm{HR}=0.56,95 \% \mathrm{Cl}: 0.43-0.74$ & 546 \\
\hline \multirow[t]{6}{*}{$\mathrm{Hg}$ (low vs. high) $)^{[10-12,14,15,59]}$} & Cytokine & & $R R=1.4, P<0.001$ & 782 \\
\hline & INF $\alpha$ & & $\mathrm{RR}=1.53, P<0.0001$ & 463 \\
\hline & Untreated & & Shorter, $P<0.001$ & 308 \\
\hline & & & $H R=1.66, P=0.005$ & 416 \\
\hline & & & $R R=2.33, P<0.0001$ & 612 \\
\hline & & & $\mathrm{RR}=1.56, P<0.0001$ & 3547 \\
\hline \multirow[t]{3}{*}{ LDH (high vs. low) $)^{[10,12,15]}$} & INF $\alpha$ & & $\mathrm{RR}=3.23, P<0.0001$ & 463 \\
\hline & & & $\mathrm{RR}=1.67, P=0.001$ & 544 \\
\hline & & & $\mathrm{RR}=1.2, P<0.0001$ & 2360 \\
\hline \multirow[t]{2}{*}{ LDH (low vs. high) ${ }^{[60]}$} & $N+I p$ & & $\mathrm{HR}=0.50,95 \% \mathrm{Cl}: 0.30-0.82$ & 550 \\
\hline & $\mathrm{S}$ & & $\mathrm{HR}=0.25,95 \% \mathrm{Cl}: 0.15-0.41$ & 546 \\
\hline \multirow[t]{2}{*}{ Neutrophil count (high vs. low) ${ }^{[12,59]}$} & Untreated & $\mathrm{HR}=2.04, P<0.001$ & $\mathrm{HR}=2.61, P<0.001$ & 416 \\
\hline & & & $\mathrm{RR}=4.58, P<0.0001$ & 583 \\
\hline Neutrophil count (low vs. high) ${ }^{[14]}$ & Cytokine & & $\mathrm{RR}=1.403, P=0.004$ & 782 \\
\hline \multirow[t]{3}{*}{ NLR (high vs. low) ${ }^{[17,61]}$} & $\mathrm{ICl}$ & $\mathrm{HR}=2.20,95 \% \mathrm{Cl}: 1.61-3.01$ & $\mathrm{HR}=3.92,95 \% \mathrm{Cl}: 2.00-7.69$ & $6461 \%$ \\
\hline & Por $S$ & & $\mathrm{HR}=1.70, P<0.001$ & $276 \$$ \\
\hline & & $\mathrm{HR}=2.09, P<0.001$ & $\begin{array}{l}\mathrm{HR}=1.90, P<0.001 \\
(\text { CSS HR } 2.31, P<0.001)\end{array}$ & 5768 \\
\hline \multirow[t]{2}{*}{ NLR (low vs. high) ${ }^{[60]}$} & $N+\operatorname{lp}$ & & $\mathrm{HR}=0.61,95 \% \mathrm{Cl}: 0.42-0.81$ & 550 \\
\hline & $S$ & & $\mathrm{HR}=0.55,95 \% \mathrm{Cl}: 0.42-0.72$ & 546 \\
\hline Platelets (high vs. low) $)^{[12]}$ & & & $\mathrm{RR}=2.56, P<0.0001$ & 607 \\
\hline \multirow[t]{2}{*}{ PLR (high vs. low) ${ }^{[17,62]}$} & $\operatorname{ccRCC}$ & & $\begin{array}{l}\mathrm{HR}=1.35, P<0.001 \\
(\mathrm{CSS} H R=1.32, P<0.001)\end{array}$ & 1505 \\
\hline & Por $S$ & & $\mathrm{HR}=1.57, P=0.002$ & $276 \ddagger$ \\
\hline s-TATI (high vs. low) ${ }^{[19]}$ & & & $\begin{array}{l}\mathrm{HR}=1.01, P=0.03 \\
(\mathrm{CSS} H R=1.01, P=0.004)\end{array}$ & 132 \\
\hline \multirow[t]{2}{*}{ TIMP-1 mRNA (high vs. low) ${ }^{[16,22]}$} & & & $\mathrm{HR}=1.0,95 \% \mathrm{Cl}: 1.0-1.0$ & 123 \\
\hline & & & Associated, $P=0.030$ & 61 \\
\hline VEGF (continuous) ${ }^{[20]}$ & Placebo & Shorter, $P=0.0231$ & Shorter, $P=0.0416$ & 452 \\
\hline VEGF (high vs. low) ${ }^{[20]}$ & Sorafenib & & $P=0.0145$ & 451 \\
\hline WBC (high vs. low) ${ }^{[15]}$ & & & $\mathrm{RR}=1.37, P<0.0001$ & 2261 \\
\hline
\end{tabular}

Total sample size of study ( $n$ of direct comparison not available). Grey Cell: positive association; White Cell: negative association; ICl: immune checkpoint inhibitor, INF $\alpha$ : interferon alpha, Ip: ipilimumab; N: nivolumab; P: pazopanib; S: sunitinib; CSS: cancer specific survival; DFS: disease free survival; HR: hazard ratio; OS: overall survival; PFS: progression free survival; RR: relative risk; ALP: alkaline phosphatase; Ca: calcium; COP-NLR: combined platelet count and neutrophil to lymphocyte ratio; CRP: C-reactive protein; Hg: hemoglobin; LDH: lactate dehydrogenase; NLR: neutrophil to lymphocyte ratio; ccRCC: clear cell RCC; PLR: platelet to lymphocyte ratio; s-TATI: serum tumor-associated trypsin inhibitor; TIMP: tissue inhibitor matrix metalloproteinase; VEGF: vascular endothelial growth factor; WBC: white blood cell.

the prognostic value of these biomarkers in predicting PFS, OS, and CSS. 
Table 2. Gene mutation, gene expression, and histologic prognostic biomarkers

\begin{tabular}{|c|c|c|c|c|c|}
\hline & Mutation biomarker & Cohort therapy or histology & PFS/DFS & os & $n$ \\
\hline \multirow[t]{12}{*}{ Gene mutation } & $B A P 1$ (vs. WT) $)^{[23]}$ & Anti-VEGF & & 28.7 vs. not reached, $P=0.02$ & 105 \\
\hline & CDKN2A (vs. WT) $)^{[24]}$ & Papillary RCC & & Shorter, $P<0.0001$ & 161 \\
\hline & $C I M P / F H(v s . W T)^{[24]}$ & Papillary RCC & & Shorter, $P<0.0001$ & 161 \\
\hline & $\operatorname{ERV}(2282,3382)$ (continuous) ${ }^{[25]}$ & $\mathrm{N}$ & Associated, $P<0.05$ & Associated, $P<0.05$ & 181 \\
\hline & PBRM-1 LOF (vs. WT) $)^{[25,31,32]}$ & N & $\mathrm{HR}=0.067, P=0.03$ & $H R=0.65, P=0.03$ & 189 \\
\hline & & N & Associated, $P=0.0056$ & Associated, $P<0.001$ & 261 \\
\hline & & $N$ & Longer, $P=0.029$ & Longer, $P=0.0074$ & 35 \\
\hline & PBRM-1 LOF + pancreatic mets (vs. WT) ${ }^{[63]}$ & Anti-angiogenic & $\mathrm{HR}=0.34, P=0.007$ & & 12 \\
\hline & & $N$ & $\mathrm{HR}=2.15, P=0.034$ & & 9 \\
\hline & & & & $\mathrm{HR}=0.25, P<0.001$ & 31 \\
\hline & TERT (vs. WT) $)^{[23]}$ & Anti-VEGF & & 29.6 months vs. 52.6 months, $P=0.03$ & 105 \\
\hline & $T M B$ (high vs. low) ${ }^{[45]}$ & $\operatorname{ccRCC}$ & Shorter, $P<0.05$ & Shorter, $P<0.05$ & 1118 \\
\hline \multirow[t]{3}{*}{ Gene expression } & ERV (high vs. low) ${ }^{[35]}$ & N & 7 months vs. 2.6 months, $P=0.01$ & & 99 \\
\hline & ERV3-2 (high vs. low) ${ }^{[36]}$ & $\mathrm{ICl}$ & $\mathrm{HR}=0.15,95 \% \mathrm{Cl}: 0.05-0.44$ & & 24 \\
\hline & NQO1 expression (high vs. low) ${ }^{[24]}$ & Papillary RCC & & Shorter, $P=0.001$ & 161 \\
\hline \multirow[t]{5}{*}{ Histology } & CAIX $\leq 85 \%(v s .>85 \%)^{[37]}$ & & & $($ CSS HR $=3.10, P<0.001)$ & 321 \\
\hline & 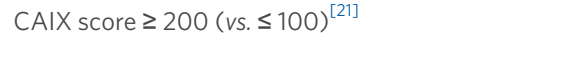 & & $\mathrm{HR}=0.69, P=0.01$ & $\begin{array}{l}\mathrm{HR}=0.60, P=0.01 \\
(\mathrm{CSS} H \mathrm{HR}=0.69, P=0.01)\end{array}$ & 813 \\
\hline & CD8+ density in Tumor Center (higher vs. lower) ${ }^{[28]}$ & S & $\mathrm{HR}=0.62,95 \% \mathrm{Cl}: 0.47-0.82$ & & $804^{\prime}$ \\
\hline & Type 1 macrophage infiltration (high vs. low) ${ }^{[38]}$ & Anti-angiogenic TKIs & & $\mathrm{HR}=1.54,95 \% \mathrm{Cl}: 1.17-2.03$ & 409 \\
\hline & Type 2 macrophage infiltration (high vs. low) ${ }^{[38]}$ & Anti-angiogenic TKIs & $\mathrm{HR}=1.40,95 \% \mathrm{Cl}: 1.09-1.78$ & $\mathrm{HR}=1.38,95 \% \mathrm{Cl}: 1.06-1.81$ & 409 \\
\hline
\end{tabular}

$\uparrow$ Total sample size of patients with measured biomarker ( $n$ of direct comparison not available). Grey Cell: Positive association; White Cell: negative association; OS: overall survival; ICI: immune checkpoint inhibitor; N: nivolumab; S: sunitinib; RCC: renal cell carcinoma; ccRCC: clear cell RCC; DFS: disease free survival; HR: hazard ratio; CSS: cancer specific survival; PFS: progression free survival; BAP: ubiquitin carboxyl-terminal hydrolase; VEGF: vascular endothelial growth factor; LOF: loss of function; CAIX: carbonic anhydrase IX; CDKN: cyclin dependent kinase inhibitor; CIMP: CpG island methylator phenotype; FH: fumarate hydratase; TKIs: tyrosine kinase inhibitors; PBRM-1: polybromo-1; TERT: telomerase reverse transcriptase; TMB: tumor mutational burden.

\section{PREDICTIVE BIOMARKERS}

Biomarkers predictive of ORR or TTF are limited. Low hemoglobin and high neutrophils have been associated with reduced TTF in patients on cytokine therapy ${ }^{[14]}$. In the more contemporary era of targeted therapy, elevated CRP and MET mutations have been associated with improved response to anti-VEGFR therapy ${ }^{[1,39]}$. PBRM-1 mutations and lack of BAP1 mutations have been associated with improved response to anti-VEGF therapy ${ }^{[23]}$. Mutations in the $m T O R$ pathway (TSC1, TSC2, MTOR) and expression of PTEN have been associated with improved response to mTOR inhibitors ${ }^{[40-42]}$. 
More relevant to the era of checkpoint inhibitors, TERT promoter mutations may be predictive of resistance to ICI, as one study found TERT promoter mutations to be enriched in patients experiencing no clinical benefit in the ICI cohort ${ }^{[43]}$. High expression of hERV has been associated with improved response to ICI and nivolumab ${ }^{[35,36]}$. High expression of a 5-Gene panel (FOXP3, CCR4, KLRK1, ITK, and TIGIT) has been associated with improved response to $\mathrm{ICI}^{[44]}$. $P B R M-1$ LOF mutations have been associated with longer OS and PFS and increased ORR in patients receiving nivolumab monotherapy ${ }^{[25,31-33]}$, but no significant difference in OS or PFS in patients receiving everolimus, sunitinib, or combination therapy ${ }^{[27,28,32,33]}$. However, these findings are not universally consistent as $P B R M-1$ mutations have also been associated with decreased ORR in patients receiving atezolumab monotherapy ${ }^{[33]}$ and improved TTF in patients receiving anti-VEGF therapy ${ }^{[23]}$. TMB has not been associated with differential ORR to ICI, nivolumab, or everolimus $^{[25,26,45,46]}$.

Overall, CRP and mutations in MET, PBRM-1, and BAP1 be associated with improved response to TKIs $^{[18,23,39]}$, while mutations in the $m$ TOR pathway and expression of PTEN may be associated with improved response to mTOR inhibitors ${ }^{[40-42]}$. TERT promoter mutations, hERV expression, and T-effector expression may be associated with improved response to $\operatorname{ICI}^{[3,3,36,43,44]}$. Table 3 and Supplementary Table 3 list all identified data depicting the value of these biomarkers in predicting response to various treatments.

\section{SELECT GENE EXPRESSION SIGNATURES AS PROGNOSTIC AND PREDICTIVE BIOMARKERS}

Aberrantly upregulated VEGF pathways cause angiogenesis necessary for continued tumor growth, while PDL1 expression by tumor and tumor-infiltrating cells suppresses the immune response to the tumor. As these two aspects of the mRCC disease state have been increasingly well-defined, a number of GES reflective of angiogenic and immunogenic pathways have been evaluated for their prognostic and predictive implications across multiple large databases of patients with mRCC. In 2019, McDermott et al. ${ }^{[29]}$ defined three such GES in an analysis of the IMmotion 150 cohort that included genetic expression related to angiogenesis (coined, "IMmotion 150 Angio", including expression of VEGFA, KDR, ESM1, PECAM1, ANGPTL4, CD34), myeloid inflammation (coined "IMmotion 150 Myeloid", including IL-6, CXCL1, CXCL2, CXCL3, CXCL8, and PTGS2), and immune activation including effector T-cell (Teff) presence and function, IFN- $\gamma$ response, checkpoint inhibitors, and antigen presentation (coined "IMmotion 150 Teff", including CD8A, EOMES, PRF1, IFNG, and CD274). Similarly, in 2020, Motzer et al. ${ }^{[28]}$ defined two GES in an analysis of the JAVELIN Renal 101 cohort that analyzed the expression of 26 genes each, coined "Renal 101 Immuno" (most similar to IMmotion 150 Teff) and "Renal 101 Angio". The extent to which high expression $v$ s. low expression (as defined by gene expression $\geq$ or $<$ median) of these five GES is associated with OS, PFS, or ORR has been examined across the IMmotion 150 and 151 cohorts, the JAVELIN phase 1 and RENAL 100 and 101 cohorts, and the CheckMate 214 cohort as depicted in Table 4 and Supplementary Table 4.

Examining cancer angiogenesis, high $v s$. low expression of both the IMmotion 150 Angio and the JAVELIN Renal 101 Angio GES have been associated with improved PFS and ORR in patients receiving sunitinib ${ }^{[27,29,47]}$. However, in patients receiving combination nivolumab + ipilimumab therapy, those with high expression of IMmotion 150 Angio demonstrated decreased $\mathrm{ORR}^{[27]}$, and in patients with low IMmotion 150 Angio receiving combination atezolumab + bevacizumab vs. sunitinib, decreased PFS has been shown ${ }^{[29]}$. Furthermore, high IMmotion 150 Angio GES has been associated with favorable (vs. intermediate/poor) risk $^{[47]}$. Finally, Beuselinck et al. ${ }^{[48]}$ established an angiogenic GES that has been associated with improved ORR to anti-angiogenic therapy across three cohorts ${ }^{[38]}$. Thus, while these angiogenic GES may predict improved response to targeted anti-angiogenic therapy compared with ICI or 
Table 3. Predictive biomarkers

\begin{tabular}{|c|c|c|c|c|c|}
\hline & Biomarker & Cohort therapy or histology & TTF & ORR & $n$ \\
\hline \multirow[t]{10}{*}{ Gene mutations } & $B A P 1(v s . W T)^{[23]}$ & anti-VEGF & 6.4 months vs. 11.0 months, $P=0.01$ & & 105 \\
\hline & MET GOF (vs. WT $)^{[39]}$ & Papillary RCC, on foretinib & & $50 \%$ vs. $9 \%$, no $P$ & 67 \\
\hline & $m T O R(v s . \mathrm{WT})^{[42]}$ & mTOR inhib & & $\mathrm{OR}=0.08,95 \% \mathrm{Cl}: 0.008-0.79$ & 87 \\
\hline & $m T O R, T S C 1, T S C 2$ (vs. WT) $)^{[40]}$ & mTOR inhib & & Associated, $P=0.06$ & 79 \\
\hline & PBRM-1 LOF (vs. WT $)^{[23,31,33]}$ & Anti-PD- $1 \pm$ Anti-CTLA-4 & & Increased, $P=0.0071$ & 63 \\
\hline & & Anti-VEGF & 12 months vs. 6.9 months, $P=0.01$ & & 105 \\
\hline & & $\mathrm{N}$ & & Increased, no $P$ & $442 \dagger$ \\
\hline & & $\mathrm{N}$ & & Increased, $P=0.012$ & 35 \\
\hline & & At & & Decreased, $P=0.04$ & 105 \\
\hline & & $A t+B$ & & Decreased, $P=0.04$ & 96 \\
\hline \multirow[t]{5}{*}{ Gene expression } & PTEN (low vs. high) ${ }^{[42]}$ & mTOR inhib & & $\mathrm{OR}=0.16,95 \% \mathrm{Cl}: 0.04-0.62$ & 53 \\
\hline & ERV (high vs. low) ${ }^{[35]}$ & $\mathrm{N}$ & & $35.6 \%$ vs. $12.5 \%, P=0.036$ & 99 \\
\hline & ERV3-2 (high vs. low) ${ }^{[36]}$ & $\mathrm{ICl}$ & & $\mathrm{OR}=45.0,95 \% \mathrm{Cl}: 3.5-584.3$ & 24 \\
\hline & T-effector expression (high vs. low) ${ }^{[50]}$ & $\mathrm{S}$ & 11.9 months vs. 28.0 months & $31 \%$ vs. $2 \%, P=0.001$ & 232 \\
\hline & FOXP3, CCR4, KLRK1, ITK, and TIGIT (high vs. low) ${ }^{[44]}$ & $\mathrm{ICl}$ & & $31 \%$ vs. $2 \%, P=0.001$ & 86 \\
\hline \multirow[t]{3}{*}{ Serum marker } & $\mathrm{CRP}>5 \mathrm{mg} / \mathrm{L}(v \mathrm{ss} . \leq 5 \mathrm{mg} / \mathrm{L})^{[18]}$ & $\mathrm{S}$ & & $61 \%$ vs. $32 \%$ & 200 \\
\hline & $\mathrm{Hg}$ (low vs. high) $)^{[14]}$ & Cytokine & $\mathrm{RR}=1.51, P=0.024$ & & 782 \\
\hline & Neutrophils $\leq 7500 / \mathrm{mL}$ (vs. $>7500 / \mathrm{mL})^{[14]}$ & Cytokine & $\mathrm{RR}=2.13, P=0.003$ & & 782 \\
\hline
\end{tabular}

$\dagger$ Total sample size of patients with measured biomarker ( $n$ of direct comparison not available). Grey Cell: Positive association; White Cell: negative association; TTF: time to treatment failure; At: atezolumab; B: bevacizumab; ICl: immune checkpoint inhibitor; RCC: renal cell carcinoma; WT: wild type; N: nivolumab; S: sunitinib; ORR: overall response rate; RR: relative risk; BAP: ubiquitin carboxyl-terminal hydrolase; CRP: Creactive protein; CTLA: cytotoxic T-lymphocyte-associated protein; Hg: hemoglobin; PTEN: phosphatase and tensin homolog; VEGF: vascular endothelial growth factor; LOF: loss of function; GOF: gain of function; MET: mesenchymal to epithelial transition; mTOR: mechanistic target of rapamycin; PBRM-1: polybromo-1; TSC: tuberous sclerosis.

combination therapy, the application of this signature may be less relevant to contemporary practice since first-line systemic therapies are often combination ICI therapy (ipilimumab with nivolumab) or combinations of TKI with ICI.

Related to immune response and inflammation, high IMmotion 150 Myeloid has been associated with poorer PFS in patients receiving atezolumab or atezolumab + bevacizumab, but not sunitinib, nivolumab + ipilimumab, or avelumab + axitinib ${ }^{[27-29]}$. High IMmotion 150 Myeloid is associated with worse PFS in patients receiving atezolumab $v s$. sunitinib, but not atezolumab + bevacizumab $v s$. sunitinib ${ }^{[8,29]}$. High IMmotion 150 Teff has been associated with improved PFS and ORR in patients receiving atezolumab + bevacizumab but not sunitinib, atezolumab, nivolumab + ipilimumab, or avelumab + axitinib ${ }^{[27-29]}$. High IMmotion 150 Teff is associated with intermediate/poor ( $v s$. favorable) risk ${ }^{[47]}$, and with improved PFS in patients receiving atezolumab vs. bevacizumab, but 
Table 4. Select gene expression signatures as predictive and prognostic biomarkers

\begin{tabular}{|c|c|c|c|c|}
\hline Biomarker & Cohort therapy or histology & PFS/DFS & ORR & $n$ \\
\hline \multirow[t]{5}{*}{ IMmotion 150 Angio (high vs. low) ${ }^{[27-29,47]}$} & $\mathrm{N}+\mathrm{Ip}$ & & Decreased, no $P$ & $213 \dagger$ \\
\hline & S & $\mathrm{HR}=0.31,95 \% \mathrm{Cl}: 0.18-0.55$ & $46 \%$ vs. $9 \%, P<0.001$ & 75 \\
\hline & $\mathrm{s}$ & $\mathrm{HR}=0.64,95 \% \mathrm{Cl}: 0.48-0.85$ & & 370 \\
\hline & $\mathrm{s}$ & $\mathrm{HR}=0.58,95 \% \mathrm{Cl}: 0.37-0.92$ & Increased, no $P$ & $213 \dagger$ \\
\hline & S & $\mathrm{HR}=0.59,95 \% \mathrm{Cl}: 0.47-0.75$ & & $823 \%$ \\
\hline IMmotion 150 Angio (low) $)^{[29]}$ & $A t+B(v s . S)$ & $\mathrm{HR}=0.59,95 \% \mathrm{Cl}: 0.35-0.98$ & & 88 \\
\hline \multirow[t]{2}{*}{ IMmotion 150 Myeloid (high vs. low) ${ }^{[29]}$} & At & $\mathrm{HR}=2.98,95 \% \mathrm{Cl}: 1.68-5.29$ & & $263 \dagger$ \\
\hline & $A t+B$ & $\mathrm{HR}=1.71,95 \% \mathrm{Cl}: 1.01-2.88$ & & $263 \dagger$ \\
\hline IMmotion 150 Myeloid (high) ${ }^{[29]}$ & At (vs. S) & $\mathrm{HR}=2.03,95 \% \mathrm{Cl}: 1.21-3.40$ & & $263 \dagger$ \\
\hline IMmotion 150 Teff (high vs. low) ${ }^{[29]}$ & $A t+B$ & $\mathrm{HR}=0.50,95 \% \mathrm{Cl}: 0.30-0.86$ & $49 \%$ vs. $16 \%, P=0.002$ & 88 \\
\hline \multirow[t]{2}{*}{ IMmotion 150 Teff (high) ${ }^{[29,47]}$} & $A t+B(v s . S)$ & $\mathrm{HR}=0.55,95 \% \mathrm{Cl}: 0.32-0.95$ & & 86 \\
\hline & $A t+B(v s . S)$ & $\mathrm{HR}=0.76,95 \% \mathrm{Cl}: 0.59-0.99$ & & $823:$ \\
\hline IMmotion 150 Teff/Myeloid (high/high) ${ }^{[29]}$ & $A t+B(v s . A t)$ & $\mathrm{HR}=0.25,95 \% \mathrm{Cl}: 0.10-0.60$ & & 41 \\
\hline IMmotion 150 Teff/Myeloid high/high (vs. high/low) ${ }^{[29]}$ & At & $\mathrm{HR}=3.82,95 \% \mathrm{Cl}: 1.70-8.60$ & & 46 \\
\hline JAVELIN Renal 101 Angio (high vs. low) ${ }^{[28]}$ & S & $\mathrm{HR}=0.56,95 \% \mathrm{Cl}: 0.42-0.74$ & & 370 \\
\hline \multirow[t]{3}{*}{ JAVELIN Renal 101 Immuno (high vs. low) ${ }^{[28]}$} & A & Longer, $P=0.007$ & & 53 \\
\hline & $A+A x$ & $\mathrm{HR}=0.36,95 \% \mathrm{Cl}: 0.16-0.81$ & & 55 \\
\hline & $A+A x$ & $\mathrm{HR}=0.60,95 \% \mathrm{Cl}: 0.44-0.83$ & & 350 \\
\hline \multirow[t]{3}{*}{ Beuselinck Angio (high vs. low) ${ }^{[38,48]}$} & Anti-angiogenic TKIs & & Improved, $P=0.03$ & 409 \\
\hline & $\mathrm{S}$ & & Improved, $P=0.017$ & 53 \\
\hline & S & & Improved, $P<0.05$ & 104 \\
\hline
\end{tabular}

$\uparrow$ Total sample size of patients with measured biomarker. + Total sample size of study ( $n$ of direct comparison not available). Grey Cell: Positive association; White Cell: negative association; A: avelumab; At: atezolumab; Ax: axitinib; B: bevacizumab; Ip: ipilimumab; N: nivolumab; S: sunitinib; DFS: disease free survival; HR: hazard ratio; ORR: overall response rate; PFS: progression free survival.

not atezolumab vs. sunitinib ${ }^{[2,47]}$. High expression of JAVELIN Renal 101 Immuno, which consists of similar genes to IMmotion 150 Teff, is associated with improved PFS in patients receiving avelumab or avelumab + axitinib, but not sunitinib ${ }^{[28]}$. To further elucidate the prognostic and predictive value of immune response and inflammation, McDermott et al. ${ }^{[29]}$ performed a combined analysis of high and low IMmotion 150 Myeloid and Teff ${ }^{[28]}$. Within the Myeloid ${ }^{\text {high }}$, Teff ${ }^{\text {tigh }}$, subgroup, improved PFS was observed among those receiving atezolumab + bevacizumab vs. atezolumab alone (HR = 0.25, 95\%CI: 0.01-0.60), but not among the Myeloid ${ }^{\text {low }}$, Teff ${ }^{\text {high }}$ subgroup $^{[20]}$. This may suggest that combination (targeted + ICI) therapy to ICI may improve treatment response in this Myeloid $^{\text {high }}$, Teff ${ }^{\text {high }}$ subgroup over ICI monotherapy. Notably, Motzer et al. ${ }^{[28]}$ found no difference in PFS between patients with IMmotion 150 Myeloid ${ }^{\text {high }}$, 
Teff $^{\text {high }} v$ s. Myeloid ${ }^{\text {low }}$, Teff ${ }^{\text {high }}$ GES in the JAVELIN Renal 101 cohort in either the avelumab + axitinib arm, or the sunitinib monotherapy arm, suggesting that the Myeloid ${ }^{\text {high }}$, Teff ${ }^{\text {high }}$ subgroup may be most resistant to ICI monotherapy rather than targeted monotherapy.

While the prognostic and predictive value of these GES requires further validation, we found the strongest consensus for angiogenic GES (IMmotion 150 Angio, JAVELIN Renal 101 Angio) as biomarkers predictive of improved response to sunitinib and for immunogenic GES (IMmotion 150 Teff, JAVELIN Renal 101 Immuno) as biomarkers predictive of improved response to ICI therapy. Additionally, myeloid inflammation GES (IMmotion Teff, Myeloid) may predict improved response to combination anti-VEGF + ICI therapy vs. ICI therapy alone. Table 4 and Supplementary Table 4 list all GES biomarkers associated with predictive or prognostic outcomes.

\section{PDL1 STATUS AS A PROGNOSTIC AND PREDICTIVE BIOMARKER}

As the principal biologic target of many of the ICIs, the expression of PDL1 on renal tumor cells has received significant attention as a potential prognostic and predictive biomarker. Prognostically, a metaanalysis in 2020 reported that PDL1 expression of tumor cells was positively associated with both OS (HR = 1.98, 95\%CI: $1.22-3.22)$ and DFS (HR $=3.70,95 \% \mathrm{CI}: 2.07-6.62)^{[49]}$. These findings are notable because tumors with high expression of PDL1 have been previously shown to demonstrate aggressive behavior ${ }^{[50-58]}$. The improved OS in PDL1-expressing tumors in the era of ICIs possibly occurs because PDL1 expression may also predict tumor response to immunotherapy.

A recent 2020 meta-analysis included 4635 patients across six randomized controlled trials (RCTs) published before May 2018 with available PDL1 expression data and compared ICI vs. standard of care therapy (SOC). Regardless of PDL1 expression level, ICI therapy improved both PFS and OS compared to SOC. However, in PDL1 positive patients receiving ICI, PFS was improved $v s$. SOC (HR $=0.75,95 \% \mathrm{CI}$ : $0.63-0.89, P<0.0001)$ but $\mathrm{OS}$ was not $(\mathrm{HR}=0.72$, CI: 0.63-0.81, $P=0.63)$. Since this meta-analysis, two of the included RCTs have published longer-term follow-up data on the effect of PDL1 status on response to ICI without significant change to earlier-published data. Furthermore, other studies assessing response to ICI based on PDL1 status report both significant [Table 5] and non-significant [Supplementary Table 5] associations between differential PDL1 expression and PFS and OS.

Overall, we found the strongest consensus for PDL1 as a prognostic biomarker for OS and PFS. Notably, PDL1 expression is dynamic. Therefore, the assessed tissues (primary tumor $v s$. metastasis) and timing of tissue acquisition (especially if primary tumor resection occurs long before evidence of metastasis) may impact PDL1 expression, and therefore the accuracy of assessment as a biomarker. Table 5 and Supplementary Table 5 listed all identified data depicting the values of PDL1 as a prognostic or predictive biomarker associated with PFS, OS, or CSS.

\section{CONCLUSION}

We reviewed the serum, gene mutation, genetic expression, and histologic biomarkers that predict response to treatment and prognosticate clinical outcomes. Current survival models may be improved by incorporation of newly proven biomarkers, allowing providers to give more accurate and individualized prognosis to patients. Future predictive models may be built to allow oncologists to prescribe the most effective treatment regimens for an individual patient's tumor and biologic profile. It is clear that patients with mRCC will benefit from continued measurement of biomarkers in large clinical trials assessing clinical responses to various treatment regimens in patients with $\mathrm{mRCC}$, and their incorporation into increasingly personalized predictive tools. 
Table 5. PDL1 status as a predictive and prognostic biomarker

\begin{tabular}{|c|c|c|c|c|}
\hline Biomarker & Cohort therapy or histology & PFS/DFS & OS (CSS) & $n$ \\
\hline PDL1 (neg vs. pos) ${ }^{[60]}$ & $\mathrm{S}$ & & $\mathrm{HR}=0.70,95 \% \mathrm{Cl}: 0.52-0.93$ & 546 \\
\hline \multirow[t]{6}{*}{ PDL1 (pos vs. neg) ${ }^{[9,28,45,50,51]}$} & $\operatorname{ccRCC}$ & Shorter, $P=0.0027$ & Shorter, $P=0.002$ & 537 \\
\hline & $\mathrm{ICl}, \mathrm{S}$, or $\mathrm{E}$ & $\mathrm{HR}=0.75,95 \% \mathrm{Cl}: 0.63-0.89$ & $\mathrm{HR}=0.72,95 \% \mathrm{Cl}: 0.63-0.81$ & 4635 \\
\hline & $\mathrm{P}$ & & Median 15 months vs. 36 months, $P=0.03$ & 221 \\
\hline & s & & Median 15 months vs. 28 months, $P=0.03$ & 232 \\
\hline & s & $\mathrm{HR}=1.57,95 \% \mathrm{Cl}: 1.16-2.14$ & & $804 \uparrow$ \\
\hline & & & $\begin{array}{l}\mathrm{RR}=2.37, P<0.001 \\
(\mathrm{CSS} \text { RR }=3.92, P<0.001)\end{array}$ & 306 \\
\hline \multirow[t]{2}{*}{ PDL1 (neg) ${ }^{[9,64]}$} & $\mathrm{ICl}(v s . \mathrm{S}$ or $\mathrm{E})$ & & $\mathrm{HR}=0.73,95 \% \mathrm{Cl}: 0.62-0.87$ & 2597 \\
\hline & $N(v s . E)$ & & $\mathrm{HR}=0.77,95 \% \mathrm{Cl}: 0.60-0.97$ & 575 \\
\hline \multirow[t]{8}{*}{ PDL1 (pos) ${ }^{[9,30,65-68]}$} & $A+A x(v s . S)$ & $\mathrm{HR}=0.63,95 \% \mathrm{Cl}: 0.49-0.81$ & & 886 \\
\hline & $A+A x(v s . S)$ & $\mathrm{HR}=0.62,95 \% \mathrm{Cl}: 0.49-0.78$ & & 560 \\
\hline & $A+A x v s . S$ & $\mathrm{HR}=0.61,95 \% \mathrm{Cl}: 0.47-0.79$ & & 560 \\
\hline & $A t+B(v s . S)$ & $\mathrm{HR}=0.74,95 \% \mathrm{Cl}: 0.57-0.96$ & & 362 \\
\hline & $\mathrm{ICl}($ vs. S or E) & & $\mathrm{HR}=0.68,95 \% \mathrm{Cl}: 0.54-0.87$ & 2038 \\
\hline & $N+I p v s . S$ & $\mathrm{HR}=0.46,95 \% \mathrm{Cl}: 0.31-0.68$ & & 214 \\
\hline & $\mathrm{Pm}+\mathrm{Ax}(v s . S)$ & $\mathrm{HR}=0.62,95 \% \mathrm{Cl}: 0.47-0.80$ & $\mathrm{HR}=0.54,95 \% \mathrm{Cl}: 0.35-0.84$ & 497 \\
\hline & Sarcomatoid, At + B (vs. S) & $\mathrm{HR}=0.45,95 \% \mathrm{Cl}: 0.26-0.77$ & & 86 \\
\hline PDL1 $\geq 5 \%$, lymphocytes $(v s .<5 \%)^{[51,58]}$ & & & $\operatorname{CSS~RR~}=4.53, P<0.001$ & 196 \\
\hline PDL1 H-Score > 55 and intratumor CD8- positive T-cell counts $>300(v s . \leq 55 \text { and } \leq 300)^{[50]}$ & $\mathrm{P}$ & & 9.6 months vs. 36.8 months & 221 \\
\hline
\end{tabular}

Total sample size of study ( $n$ of direct comparison not available). Grey Cell: Positive association; White Cell: negative association; A: avelumab; At: atezolumab; Ax: axitinib; B: bevacizumab; E: everolimus; ICI: immune checkpoint inhibitor; Ip: ipilimumab; N: nivolumab; P: pazopanib; Pm: pembrolizumab; S: sunitinib; ccRCC: clear cell renal cell carcinoma; CSS: cancer specific survival; DFS: disease free survival; HR: hazard ratio; OS: overall survival; PFS: progression free survival; RR: relative risk; PDL1: programmed death-ligand.

\section{DECLARATIONS}

Authors' contributions

Contributed to conceptualization: Blute ML

Contributed to supervision: Blute ML

Contributed to writing - review and editing: Blute ML, Lee RJ, Cone EB, Briggs LG

Contributed to methodology supervision: Cone EB 
Contributed to methodology, data curation, writing - original draft: Briggs LG

\section{Availability of data and materials}

Not applicable.

\section{Financial support and sponsorship}

None.

\section{Conflicts of interest}

Lee RJ: Astellas, Bayer, Dendreon, Exelixis, GE Heathcare, Janssen (advisory board); Janssen (research funding).

\section{Ethical approval and consent to participate \\ Not applicable.}

\section{Consent for publication}

Not applicable.

\section{Copyright}

(c) The Author(s) 2021.

\section{REFERENCES}

1. Strimbu K, Tavel JA. What are Biomarkers. Curr Opin HIV AIDS 2010;5:463-6. DOI PubMed PMC

2. Mickley A, Kovaleva O, Kzhyshkowska J, Gratchev A. Molecular and immunologic markers of kidney cancer-potential applications in predictive, preventive and personalized medicine. EPMA J 2015;6:20. DOI PubMed PMC

3. Graham J, Dudani S, Heng DYC. Prognostication in kidney cancer: recent advances and future directions. $J$ Clin Oncol 2018:JCO2018790147. DOI PubMed

4. Siegel RL, Miller KD, Jemal A. Cancer statistics, 2020. CA Cancer J Clin 2020;70:7-30. DOI PubMed

5. Sung H, Ferlay J, Siegel RL, et al. Global Cancer Statistics 2020: GLOBOCAN estimates of incidence and mortality worldwide for 36 cancers in 185 countries. CA Cancer J Clin 2021;71:209-49. DOI PubMed

6. Cohen HT, Mcgovern FJ. Renal-cell carcinoma. N Engl J Med 2005;353:2477-90. DOI PubMed

7. Cancer Stat Facts: kidney and renal pelvis cancer. Surveillance, Epidemiology, and End Results Program. Available from: https://seer.cancer.gov/statfacts/html/kidrp.html. [Last accessed on $1 \mathrm{Jul} 2021$ ].

8. Brown LC, Desai K, Zhang T, Ornstein MC. The immunotherapy landscape in renal cell carcinoma. BioDrugs 2020;34:733-48. DOI PubMed

9. Carretero-González A, Lora D, Martín Sobrino I, et al. The value of PD-L1 expression as predictive biomarker in metastatic renal cell carcinoma patients: a meta-analysis of randomized clinical trials. Cancers (Basel) 2020;12:1945. DOI PubMed PMC

10. Motzer RJ, Bacik J, Murphy BA, Russo P, Mazumdar M. Interferon-alfa as a comparative treatment for clinical trials of new therapies against advanced renal cell carcinoma. J Clin Oncol 2002;20:289-96. DOI PubMed

11. Mekhail TM, Abou-Jawde RM, Boumerhi G, et al. Validation and extension of the Memorial Sloan-Kettering prognostic factors model for survival in patients with previously untreated metastatic renal cell carcinoma. J Clin Oncol 2005;23:832-41. DOI PubMed

12. Heng DY, Xie W, Regan MM, et al. Prognostic factors for overall survival in patients with metastatic renal cell carcinoma treated with vascular endothelial growth factor-targeted agents: results from a large, multicenter study. J Clin Oncol 2009;27:5794-9. DOI PubMed

13. Heng DY, Xie W, Regan MM, et al. External validation and comparison with other models of the International Metastatic Renal-Cell Carcinoma Database Consortium prognostic model: a population-based study. Lancet Oncol 2013;14:141-8. DOI PubMed PMC

14. Négrier S, Escudier B, Gomez F, et al. Prognostic factors of survival and rapid progression in 782 patients with metastatic renal carcinomas treated by cytokines: a report from the Groupe Français d'Immunothérapie. Ann Oncol 2002;13:1460-8. DOI PubMed

15. Manola J, Royston P, Elson P, et al; International Kidney Cancer Working Group. Prognostic model for survival in patients with metastatic renal cell carcinoma: results from the international kidney cancer working group. Clin Cancer Res 2011;17:5443-50. DOI PubMed PMC

16. Peña C, Lathia C, Shan M, Escudier B, Bukowski RM. Biomarkers predicting outcome in patients with advanced renal cell carcinoma: results from sorafenib phase III Treatment Approaches in Renal Cancer Global Evaluation Trial. Clin Cancer Res 2010;16:4853-63. DOI PubMed

17. Marta GN, Velho PI, Bonadio RRC, et al. Prognostic value of systemic inflammatory biomarkers in patients with metastatic renal cell carcinoma. Pathol Oncol Res 2020;26:2489-97. DOI PubMed 
18. Beuselinck B, Vano YA, Oudard S, et al. Prognostic impact of baseline serum C-reactive protein in patients with metastatic renal cell carcinoma (RCC) treated with sunitinib. BJU Int 2014;114:81-9. DOI PubMed

19. Tornberg SV, Nisen H, Järvinen P, et al. Serum tumour associated trypsin inhibitor, as a biomarker for survival in renal cell carcinoma. Scand J Urol 2020;54:413-9. DOI PubMed

20. Escudier B, Eisen T, Stadler WM, et al. Sorafenib for treatment of renal cell carcinoma: Final efficacy and safety results of the phase III treatment approaches in renal cancer global evaluation trial. J Clin Oncol 2009;27:3312-8. DOI PubMed

21. Chamie K, Klöpfer P, Bevan P, et al. Carbonic anhydrase-IX score is a novel biomarker that predicts recurrence and survival for highrisk, nonmetastatic renal cell carcinoma: Data from the phase III ARISER clinical trial. Urol Oncol 2015;33:204.e25-33. DOI PubMed

22. Dias F, Lu A, Morais M. Plasma extracellular vesicle-derived TIMP-1 mRNA as a prognostic biomarker in clear cell renal cell carcinoma: a pilot study. Int J Mol Sci 2020;21:4624. DOI PubMed PMC

23. Carlo MI, Manley B, Patil S, et al. Genomic alterations and outcomes with VEGF-targeted therapy in patients with clear cell renal cell carcinoma. Kidney Cancer 2017;1:49-56. DOI PubMed PMC

24. Linehan WM, Spellman PT, Ricketts CJ, et al; Cancer Genome Atlas Research Network. Comprehensive molecular characterization of papillary renal-cell carcinoma. N Engl J Med 2016;374:135-45. DOI PubMed PMC

25. Braun DA, Hou Y, Bakouny Z, et al. Interplay of somatic alterations and immune infiltration modulates response to PD-1 blockade in advanced clear cell renal cell carcinoma. Nat Med 2020;26:909-18. DOI PubMed PMC

26. Wood MA, Weeder BR, David JK, Nellore A, Thompson RF. Burden of tumor mutations, neoepitopes, and other variants are weak predictors of cancer immunotherapy response and overall survival. Genome Med 2020;12:33. DOI PubMed PMC

27. Motzer RJ, Choueiri TK, Mcdermott DF, et al. Biomarker analyses from the phase III CheckMate 214 trial of nivolumab plus ipilimumab (N+I) or sunitinib (S) in advanced renal cell carcinoma (aRCC). JCO 2020;38:5009-5009. DOI

28. Motzer RJ, Robbins PB, Powles T, et al. Avelumab plus axitinib versus sunitinib in advanced renal cell carcinoma: biomarker analysis of the phase 3 JAVELIN Renal 101 trial. Nat Med 2020;26:1733-41. DOI PubMed

29. Mcdermott DF, Huseni MA, Atkins MB, et al. Clinical activity and molecular correlates of response to atezolizumab alone or in combination with bevacizumab versus sunitinib in renal cell carcinoma. Nat Med 2019;24:749-57. DOI PubMed PMC

30. Choueiri TK, Albiges L, Haanen JBAG, et al. Biomarker analyses from JAVELIN Renal 101: Avelumab + axitinib (A+Ax) versus sunitinib (S) in advanced renal cell carcinoma (aRCC). JCO 2019;37:101. DOI

31. Miao D, Margolis CA, Gao W, et al. Genomic correlates of response to immune checkpoint therapies in clear cell renal cell carcinoma. Science 2018;359:801-6. DOI PubMed PMC

32. Braun DA, Ishii Y, Walsh AM, et al. Clinical validation of PBRM1 alterations as a marker of immune checkpoint inhibitor response in renal cell carcinoma. JAMA Oncol 2019;5:1631-3. DOI PubMed PMC

33. Liu XD, Kong W, Peterson CB, et al. PBRM1 loss defines a nonimmunogenic tumor phenotype associated with checkpoint inhibitor resistance in renal carcinoma. Nat Commun 2020;11:2135. DOI PubMed PMC

34. Becerraa MF, Reznik E, Redzematovice A, et al. Comparative genomic profiling of matched primary and metastatic tumors in renal cell carcinoma maria. Eur Urol Focus 2018;6:986-94. DOI

35. Pignon J, Jegede O, Shukla SA, et al. Association of human endogenous retrovirus (hERV) expression with clinical efficacy of PD-1 blockade in metastatic clear cell renal cell carcinoma (mccRCC). JCO 2019;37:4568. DOI

36. Panda A, de Cubas AA, Stein M, et al. Endogenous retrovirus expression is associated with response to immune checkpoint blockade in clear cell renal cell carcinoma. JCI Insight 2018;3:121522. DOI PubMed PMC

37. Bui MHT, Seligson D, Han KR, et al. Carbonic anhydrase IX is an independent predictor of survival in advanced renal clear cell carcinoma: implications for prognosis and therapy. Clin Cancer Res 2003;9:802-11. PubMed

38. Hakimi AA, Voss MH, Kuo F, et al. Transcriptomic profiling of the tumor microenvironment reveals distinct subgroups of clear cell renal cell cancer: data from a randomized phase III trial. Cancer Discov 2019;9:510-25. DOI PubMed PMC

39. Choueiri TK, Vaishampayan U, Rosenberg JE, et al. Phase II and biomarker study of the dual MET/VEGFR2 inhibitor foretinib in patients with papillary renal cell carcinoma. J Clin Oncol 2013;31:181-6. DOI PubMed PMC

40. Kwiatkowski DJ, Choueiri TK, Fay AP, et al. Mutations in TSC1, TSC2, and MTOR are associated with response to rapalogs in patients with metastatic Renal Cell Carcinoma. Clin Cancer Res 2016;22:2445-52. DOI PubMed PMC

41. Voss MH, Hakimi AA, Pham CG, et al. Tumor genetic analyses of patients with metastatic renal cell carcinoma and extended benefit from mTOR inhibitor therapy. Clin Cancer Res 2014;20:1955-64. DOI PubMed PMC

42. Roldan-Romero JM, Beuselinck B, Santos M, et al; Spanish Oncology Genitourinary Group (SOGUG). PTEN expression and mutations in TSC1, TSC2 and MTOR are associated with response to rapalogs in patients with renal cell carcinoma. Int J Cancer 2020;146:1435-44. DOI PubMed

43. Dizman N, Lyou Y, Salgia N, et al. Correlates of clinical benefit from immunotherapy and targeted therapy in metastatic renal cell carcinoma: comprehensive genomic and transcriptomic analysis. J Immunother Cancer 2020;8:e00953. DOI PubMed PMC

44. Zhu J, Pabla S, Labriola M, et al. Evaluation of tumor microenvironment and biomarkers of immune checkpoint inhibitor (ICI) response in metastatic renal cell carcinoma (mRCC). JCO 2019;37:2595. DOI

45. Huang J, Li Z, Fu L, et al. RETRACTED ARTICLE: Comprehensive characterization of tumor mutation burden in clear cell renal cell carcinoma based on the three independent cohorts. J Cancer Res Clin Oncol 2021;147:1745. DOI PubMed

46. Labriola MK, Zhu J, Gupta RT, et al. Characterization of tumor mutation burden, PD-L1 and DNA repair genes to assess relationship to immune checkpoint inhibitors response in metastatic renal cell carcinoma. J Immunother Cancer 2020;8:e000319. DOI PubMed PMC 
47. Rini B, Huseni M, Atkins M, et al. Molecular correlates differentiate response to atezolizumab (atezo) + bevacizumab (bev) vs sunitinib (sun): Results from a phase III study (IMmotion151) in untreated metastatic renal cell carcinoma (mRCC). Ann Oncol 2018;29:viii724-5. DOI

48. Beuselinck B, Verbiest A, Couchy G, et al. Pro-angiogenic gene expression is associated with better outcome on sunitinib in metastatic clear-cell renal cell carcinoma. Acta Oncol 2018;57:498-508. DOI PubMed

49. Shen M, Chen G, Xie Q, et al. Association between PD-L1 expression and the prognosis and clinicopathologic features of renal cell carcinoma: a systematic review and meta-analysis. Urol Int 2020;104:533-41. DOI PubMed

50. Choueiri TK, Figueroa DJ, Fay AP, et al. Correlation of PD-L1 tumor expression and treatment outcomes in patients with renal cell carcinoma receiving sunitinib or pazopanib: results from COMPARZ, a randomized controlled trial. Clin Cancer Res 2015;21:1071-7. DOI PubMed

51. Thompson RH, Kuntz SM, Leibovich BC, et al. Tumor B7-H1 is associated with poor prognosis in renal cell carcinoma patients with long-term follow-up. Cancer Res 2006;66:3381-5. DOI PubMed

52. Boland JM, Kwon ED, Harrington SM, et al. Tumor B7-H1 and B7-H3 expression in squamous cell carcinoma of the lung. Clin Lung Cancer 2013;14:157-63. DOI PubMed

53. Bigelow E, Bever KM, Xu H, et al. Immunohistochemical staining of B7-H1 (PD-L1) on paraffin-embedded slides of pancreatic adenocarcinoma tissue. J Vis Exp 2013:4059. DOI PubMed PMC

54. Lyford-Pike S, Peng S, Young GD, et al. Evidence for a role of the PD-1:PD-L1 pathway in immune resistance of HPV-associated head and neck squamous cell carcinoma. Cancer Res 2013;73:1733-41. DOI PubMed PMC

55. Wintterle S, Schreiner B, Mitsdoerffer M, et al. Expression of the B7-related molecule B7-H1 by glioma cells: a potential mechanism of immune paralysis. C. ancer Res 2003;63:7462-7. PubMed

56. Zhang Y, Huang S, Gong D, Qin Y, Shen Q. Programmed death-1 upregulation is correlated with dysfunction of tumor-infiltrating CD8+ T lymphocytes in human non-small cell lung cancer. Cell Mol Immunol 2010;7:389-95. DOI PubMed PMC

57. Nakanishi J, Wada Y, Matsumoto K, Azuma M, Kikuchi K, Ueda S. Overexpression of B7-H1 (PD-L1) significantly associates with tumor grade and postoperative prognosis in human urothelial cancers. Cancer Immunol Immunother 2007;56:1173-82. DOI PubMed

58. Thompson RH, Gillett MD, Cheville JC, et al. Costimulatory B7-H1 in renal cell carcinoma patients: Indicator of tumor aggressiveness and potential therapeutic target. Proc Natl Acad Sci U S A 2004;101:17174-9. DOI PubMed PMC

59. Motzer RJ, Escudier B, Oudard S, et al; RECORD-1 Study Group. Phase 3 trial of everolimus for metastatic renal cell carcinoma: final results and analysis of prognostic factors. Cancer 2010;116:4256-65. DOI PubMed

60. Motzer RJ, Rini BI, Mcdermott DF, et al. Nivolumab plus ipilimumab versus sunitinib in first-line treatment for advanced renal cell carcinoma: extended follow-up of efficacy and safety results from a randomised, controlled, phase 3 trial. Lancet Oncol 2019;20:137085. DOI PubMed PMC

61. Shao Y, Wu B, Jia W, Zhang Z, Chen Q, Wang D. Prognostic value of pretreatment neutrophil-to-lymphocyte ratio in renal cell carcinoma: a systematic review and meta- analysis. BMC Urol 2020;20:90. DOI PubMed PMC

62. Yuk HD, Kang M, Hwang EC, et al; Korean Renal Cancer Study (KRoCS) Group. The platelet-to-lymphocyte ratio as a significant prognostic factor to predict survival outcomes in patients with synchronous metastatic renal cell carcinoma. Investig Clin Urol 2020;61:475-81. DOI PubMed PMC

63. Singla N, Xie Z, Zhang Z, et al. Pancreatic tropism of metastatic renal cell carcinoma. JCI Insight 2020;5:134564. DOI PubMed PMC

64. Motzer RJ, Escudier B, McDermott DF, et al; CheckMate 025 Investigators. Nivolumab versus everolimus in advanced renal-cell carcinoma. N Engl J Med 2015;373:1803-13. DOI PubMed PMC

65. Choueiri TK, Motzer RJ, Rini BI, et al. Updated efficacy results from the JAVELIN Renal 101 trial: first-line avelumab plus axitinib versus sunitinib in patients with advanced renal cell carcinoma. Ann Oncol 2020;31:1030-9. DOI PubMed

66. Rini BI, Powles T, Atkins MB, et al. Atezolizumab plus bevacizumab versus sunitinib in patients with previously untreated metastatic renal cell carcinoma (IMmotion151): a multicentre, open-label, phase 3, randomised controlled trial. Lancet 2019;393:2404-15. DOI PubMed

67. Motzer RJ, Tannir NM, McDermott DF, et al; CheckMate 214 Investigators. Nivolumab plus ipilimumab versus sunitinib in advanced renal-cell carcinoma. N Engl J Med 2018;378:1277-90. DOI PubMed PMC

68. Rini BI, Motzer RJ, Powles T, et al. Atezolizumab plus bevacizumab versus sunitinib for patients with untreated metastatic renal cell carcinoma and sarcomatoid features: a prespecified subgroup analysis of the IMmotion151 clinical trial. Eur Urol 2021;79:659-62. DOI PubMed

69. Danaher P, Warren S, Lu R, et al. Pan-cancer adaptive immune resistance as defined by the Tumor Inflammation Signature (TIS): results from The Cancer Genome Atlas (TCGA). J Immunother Cancer 2018;6:63. DOI PubMed PMC

70. Fong PC, Boss DS, Yap TA et al. Inhibition of poly(ADP-Ribose) polymerase in tumors from BRCA mutation carriers. Available from: https://www.nejm.org/doi/pdf/10.1056/NEJMoa0900212?articleTools=true. [Last accessed on 1 Jul 2021].

71. Rini BI, Plimack ER, Stus V, et al; KEYNOTE-426 Investigators. Pembrolizumab plus axitinib versus sunitinib for advanced renalcell carcinoma. N Engl J Med 2019;380:1116-27. DOI PubMed

72. Plimack ER, Rini BI, Stus V, et al. Pembrolizumab plus axitinib versus sunitinib as first-line therapy for advanced renal cell carcinoma (RCC): Updated analysis of KEYNOTE-426. JCO 2020;38:5001. DOI 